\title{
Quantitative Comparison of Glutamatergic and GABAergic Synaptic Vesicles Unveils Selectivity for Few Proteins Including MAL2, a Novel Synaptic Vesicle Protein
}

\author{
Mads Grønborg, ${ }^{1,2}$ Nathan J. Pavlos, ${ }^{1}$ Irene Brunk, ${ }^{4}$ John J. E. Chua, ${ }^{1}$ Agnieszka Münster-Wandowski, ${ }^{4}$ Dietmar Riedel, ${ }^{3}$ \\ Gudrun Ahnert-Hilger, ${ }^{4}$ Henning Urlaub, ${ }^{2}$ and Reinhard Jahn ${ }^{1}$ \\ Departments of ${ }^{1}$ Neurobiology and ${ }^{2}$ Bioanalytical Mass Spectrometry, Laboratories of ${ }^{3}$ Electron Microscopy, Max Planck Institute for Biophysical \\ Chemistry, 37077 Göttingen, Germany, and ${ }^{4}$ AG Functional Cell Biology, Institute for Integrative Neuroanatomy, Charité Centre 2 for Basic Medicine, \\ 10115 Berlin, Germany
}

Synaptic vesicles (SVs) store neurotransmitters and release them by exocytosis. The vesicular neurotransmitter transporters discriminate which transmitter will be sequestered and stored by the vesicles. However, it is unclear whether the neurotransmitter phenotype of SVs is solely defined by the transporters or whether it is associated with additional proteins. Here we have compared the protein composition of SVs enriched in vesicular glutamate (VGLUT-1) and GABA transporters (VGAT), respectively, using quantitative proteomics. Of $>450$ quantified proteins, $\sim 50$ were differentially distributed between the populations, with only few of them being specific for SVs. Of these, the most striking differences were observed for the zinc transporter ZnT3 and the vesicle proteins SV2B and SV31 that are associated preferentially with VGLUT-1 vesicles, and for SV2C that is associated mainly with VGAT vesicles. Several additional proteins displayed a preference for VGLUT-1 vesicles including, surprisingly, synaptophysin, synaptotagmins, and syntaxin 1a. Moreover, MAL2, a membrane protein of unknown function distantly related to synaptophysins and SCAMPs, cofractionated with VGLUT-1 vesicles. Both subcellular fractionation and immunolocalization at the light and electron microscopic level revealed that MAL2 is a bona-fide membrane constituent of SVs that is preferentially associated with VGLUT-1-containing nerve terminals. We conclude that SVs specific for different neurotransmitters share the majority of their protein constituents, with only few vesicle proteins showing preferences that, however, are nonexclusive, thus confirming that the vesicular transporters are the only components essential for defining the neurotransmitter phenotype of a SV.

\section{Introduction}

Signal transmission at synapses is mediated by neurotransmitters that are stored in synaptic vesicles (SVs) and released by $\mathrm{Ca}^{2+}$ dependent exocytosis. The membrane constituents of SVs are retrieved from the plasma membrane by endocytosis. SVs are then regenerated, possibly involving endosomal intermediates, and filled with neurotransmitter by means of specific vesicular neurotransmitter transporters (Sudhof, 2004; Edwards, 2007).

Membrane traffic of SVs within nerve terminals has been studied in great detail, and many proteins involved in exo- and endocytosis have been identified. Since exo-endocytotic cycling is a general hallmark of SVs in all nerve terminals independent of their release dynamics or their neurotransmitter phenotype, it is not surprising that proteins involved in SV trafficking are common constituents of all SVs in the nervous system. However, not

\footnotetext{
Received Aug. 19, 2009; revised 0ct. 13, 2009; accepted Nov. 2, 2009

M.G. is supported by a research fellowship from the Alfred Benzon Foundation. N.J.P. is supported by a National Health and Medical Research Council (Australia) CJ Martin Fellowship, ID: 463911.

Correspondence should be addressed to either Henning Urlaub, Department of Bioanalytical Mass Spectrometry, or Reinhard Jahn, Department of Neurobiology, Max Planck Institute for Biophysical Chemistry, 37077 Göttingen, Germany. E-mail: henning.urlaub@mpibpc.mpg.de or rjahn@gwdg.de.

D01:10.1523/JNEUROSCI.4074-09.2010

Copyright $\odot 2010$ the authors $\quad 0270-6474 / 10 / 300002-11 \$ 15.00 / 0$
}

only the major trafficking proteins, but many other functionally less well understood SV proteins are represented by small protein families containing several isoforms that are differentially expressed in different parts of the nervous system, such as the synapsins, synaptotagmins, synaptophysins, and SCAMPs (Jahn and Südhof, 1994; Burré and Volknandt, 2007). In general, however, it appears that each vesicle contains at least one of these isoforms, supporting the view that SVs, despite an enormous morphological and physiological diversity of nerve terminals, share a common set of membrane constituents.

In contrast, the proteins responsible for vesicular neurotransmitter uptake are largely restricted to neurons with the respective neurotransmitter phenotype. In conjunction with the biosynthetic enzymes and (at least in some cases) the plasma membrane transporters, the vesicular transporters are mainly responsible for determining the neurotransmitter that is released from the particular neuron (Ahnert-Hilger et al., 2003; Edwards, 2007). With a few notable exceptions (Fremeau et al., 2002), SVs usually contain only transporters for a single neurotransmitter. It is unclear, however, whether the vesicular neurotransmitter transporters are the only SV proteins required for defining the neurotransmitter phenotype or whether other proteins are associated with these vesicles such as cotransporters or ion channels. 
Recently, the proteome of purified SVs has been analyzed using mass spectrometry (Blondeau et al., 2004; Coughenour et al., 2004; Morciano et al., 2005; Burré et al., 2006; Takamori et al., 2006). While the results revealed an unexpected complexity of proteins involved in membrane traffic, only few previously uncharacterized proteins were identified. Furthermore, a quantitative molecular model has been constructed that is based on determining the stoichiometry of more than a dozen SV constituents (Takamori et al., 2006). However, these studies involved SV fractions isolated from whole brain, which does not take into account that there are heterogeneous populations such as those defined by the neurotransmitter phenotype.

In the present study, we have used high resolution mass spectrometry combined with chemical labeling to quantitatively compare the proteins of glutamatergic and GABAergic SVs. We have previously shown that more than a dozen major vesicle proteins are shared between these populations (Takamori et al., 2000a). Here we report that while the proteomes of VGLUT-1and VGAT-containing vesicles are remarkably similar, a few specific proteins preferentially cofractionated with either VGLUT-1 or VGAT-bearing vesicles. These include the zinc transporter $\mathrm{ZnT3}$, members of the synaptotagmin family, synaptophysin, syntaxin 1a, SV31, SV2 isoforms SV2B and SV2C, and MAL2, a recently discovered membrane protein of unknown function that so far has not been assigned to SVs.

\section{Materials and Methods}

Antibodies. MAL2 antibody was generated using a synthetic peptide (aa 13-28) coupled to keyhole limpet homocyanin. MAL2 antibody was affinity purified using the peptide used for immunization coupled to SulfoLink resin (Thermo Scientific). Antibodies against Synaptophysin (Jahn et al., 1985) synaptobrevin (VAMP) 2 (Edelmann et al., 1995), syntaxin 1A (Chapman et al., 1995), synapsin 1, synaptotagmin 1 (Brose et al., 1992), VGLUT-1 rabbit (Takamori et al., 2001), SV2A, SV2B, SV2C, Rab3a, VGLUT-2, ZnT3 (rabbit), NMDA-R, Mint, VGLUT-1 (guinea pig), VGAT (rabbit, guinea pig) were obtained from Synaptic Systems. VGAT (rabbit), VGLUT-1 (rabbit) antibodies were affinity purified using the corresponding immunogen coupled to cyanogens bromide-activated Sepharose 4B (Sigma-Aldrich).

Immunoisolation. Affinity purified VGLUT-1 or VGAT rabbit antibodies were conjugated to Eupergit $\mathrm{C} 1 \mathrm{Z}$ methacrylate microbeads (Röhm Pharmaceuticals) and used for immunoisolation as described previously (Burger et al., 1989; Takamori et al., 2000a,b). Bound SVs were eluted by incubating the beads with $0.85 \%$ RapiGest SF (Waters) in $100 \mathrm{~mm}$ triethylammonium bicarbonate (TEAB) buffer. The samples were heated for $10 \mathrm{~min}$ at $70^{\circ} \mathrm{C}$ and the supernatants were transferred to clean tubes after spinning the samples for $2 \mathrm{~min}$ at 14,000 RPM. Crude SVs (LP2 fraction) were purified according to standard procedures (Huttner et al., 1983; Hell and Jahn, 1994) (see supplemental Fig. 2, available at www.jneurosci.org as supplemental material, for overview).

Digestion and iTRAQ labeling. Eluted SVs were solubilized by RapiGest SF (Waters) and digested in-solution by trypsin as previously described (Li et al., 2007). Tryptic peptides were then tagged with iTRAQ reagent according to manufactures instructions (iTRAQ reagent kit, Applied Biosystems). VGLUT-1- and VGAT-specific SVs were tagged with iTRAQ 114 or 115, respectively (supplemental Fig. $2 B$, available at www. jneurosci.org as supplemental material).

Strong cation exchange fractionation. After digestion, the samples were fractionated on an ICAT SCX column (Applied Biosystems) according to the manufacturers' instructions. Peptides were eluted stepwise by adding $500 \mu \mathrm{l}$ of KCl-solutions of increasing concentration $(5,100,150,200,300,400,500$, 600,800 , and $1000 \mathrm{~mm}$ ) in $10 \mathrm{~mm} \mathrm{KH}_{2} \mathrm{PO}_{4}, 25 \%$ acetonitrile, $\mathrm{pH}$ 3.0. The samples were desalted on a hand made micro column with POROS Oligo R2 RP material as previously described (Thingholm and Larsen, 2009).

Mass spectrometry and quantification. The SCX-fractions were analyzed on Thermo LTQ XL Orbitrap (Thermo Fisher Scientific) coupled to an Agilent 1100 series LC-system (Agilent Technologies). Peptides were separated at a flow rate of $200-300 \mathrm{nl} / \mathrm{min}$ on a self-made reversed phase column $\left(\mathrm{C}_{18}\right.$, Reprosil, Maisch). Elution of the peptides was done with a 118 min gradient from $7.5-40 \%$ mobile phase B ( $80 \%$ acetonitrile, $0.15 \%$ formic acid). Peak lists were searched against NCBI RefSeq database using Mascot v.2.2.04 as search engine. Mass accuracy was 10 $\mathrm{ppm}$ for the parent ion and $30 \mathrm{ppm}$ for fragment ions. The peptides were constrained to be tryptic with a maximum of 2 missed cleavages. Carbamidomethylation of cysteines was considered a fixed modification, whereas oxidations of methionine residues were considered as variable modification. Quantification was done using Mascot $\mathrm{v}$ 2.2.04. The protein ratio was calculated as a weighted median ratio where peptides with a scores $>15$ were used for quantification. Only proteins quantified with unique peptides and a minimum of 3 peptides have been included.

Data normalization. When analyzing the statistical distribution of the VGLUT-1/VGAT peptide ratios from each biological replicate (Rep.1Rep.3), it showed a systematic bias due to unequal protein mixing (supplemental Fig. $3 A$, available at www.jneurosci.org as supplemental material). The data set was therefore normalized by dividing the raw peptide ratios with their median value which resulted in a balanced distribution around a 1:1 ratio (supplemental Fig. 3B, Rep.1-Rep.3, available at www.jneurosci.org as supplemental material). To determine the protein ratios that are statistically significant outliers and hence biological significant for the two subpopulations of SVs, a Box plot of the average normalized protein ratios from the biological replicates was generated (supplemental Fig. $2 \mathrm{~B}$, Ave, available at www.jneurosci.org as supplemental material). The plot represents the interquantile range (IQR) of $25-75 \%$, the center line the median, and the whiskers (horizontal lines) extend up to 1.5 -fold of the IQR. Protein ratios outside the whiskers are considered to be significant differences between VGLUT-1and VGAT-specific vesicles.

Immunoblot analysis. SDS-PAGE was performed according to Laemmli (1970) and immunoblotting was done according to Towbin et al. (1979) with minor modifications using the XCell II Module (Invitrogen). Immunoblot quantification of MAL2 was done as previously described (Bethani et al., 2007).

Triton X-114 extraction. The Triton X-114 (TX-114) extraction was performed with $150 \mu \mathrm{g}$ of homogenate from each tissue as previously described (Bordier, 1981; Schlüter et al., 2002).

Peptide competition experiment. An aliquot of MAL2 serum was either left untreated or incubated with $50 \mu \mathrm{g}$ of peptide used for immunization (CNPAVSFPAPRITLPAG) or control peptide (CTLPAGPDILRTYS). The antibodies were rotated head over head for $2 \mathrm{~h}$ at $4^{\circ} \mathrm{C}$ and subsequently used for immunoblotting.

Pronase digestion. The Pronase digestion experiment was performed with $10 \mu \mathrm{g}$ of crude SVs (LP2 fraction) as described previously (Stenius et al., 1995).

Immunofluorescence. Primary hippocampal rat neurons were seeded on poly-L-lysine coated glass coverslips at a $30 \mathrm{~K}$ density. The neurons were fixed at day 12 with $4 \%$ paraformaldehyde (PFA) and permeabilized with $0.1 \%$ Triton X-100. Antibodies used for IF were used in a 1:500 dilution.

Negative staining and embedding of Eupergit beads (electron microscopy). Negative staining of an enriched SV fraction (LP2) and electron microscopy of Immunobeads were done as previously described (Takamori et al., 2000).

Tissue preparation (immunocytochemistry). For all procedures ethical approval was obtained in accordance with the National Act on the Use of Experimental Animals (Germany). Male adult Wistar rats (300-350 g) were anesthetized by a mixture of medetomidine $(500 \mu \mathrm{g} / \mathrm{kg}$, Pfizer, Orion Pharma) and ketamine (75 mg/kg, WDT) and perfused following a protocol given by Takumi et al. (1999). Immunofluorescence microscopy: Cryostat sections (20 or $30 \mu \mathrm{m})$ were incubated with a rabbit polyclonal antiserum alone (single labeling) or in combination with a guinea pig polyclonal antiserum (double labeling). The bound primary antibodies were visualized by application of Texas Red-labeled goat antirabbit serum (Jackson Immuno Research Laboratories) alone or together 
with Alexa Fluor 488-labeled goat anti-guinea pig serum (Invitrogen) (Becher et al., 1999).

Electron microscopy (immunocytochemistry). Freeze substitution embedding followed a modification of a protocol given (Pahner et al., 2003): Brain slices (1-2 mm thick) were prepared from hippocampus and cerebellum (vermis) and washed $6 \times 10 \mathrm{~min}$ in $0.1 \mathrm{~m}$ sodium phosphate buffer $(\mathrm{PB})$ at $\mathrm{pH}$ 7.4. The slices were cryo-protected in increasing concentrations of glycerol (10-20-30\%) in PB and left overnight in 30\% glycerol at $4^{\circ} \mathrm{C}$. The tissue was frozen by plunging into hexane (Carl Roth) at a temperature of $-70^{\circ} \mathrm{C}$. The samples were transferred into cold methanol $\left(-90^{\circ} \mathrm{C}\right)$ in a freeze-substitution chamber (Leica EM AFS, Austria). The methanol was exchanged three times before the specimen was immersed overnight in anhydrous methanol at $-90^{\circ} \mathrm{C}$, containing $2 \%(\mathrm{w} / \mathrm{v})$ uranyl acetate. After rinsing several times with methanol, the temperature was gradually raised to $-50^{\circ} \mathrm{C}$ and left overnight at $-50^{\circ} \mathrm{C}$. The tissue was then infiltrated with mixtures of Lowicryl HM20 resin (Polysciences) and methanol (1:2,1:1,2:1, $1 \mathrm{~h}$ each) and finally left in pure resin overnight at $-50^{\circ} \mathrm{C}$. The samples were transferred to flat embedding molds containing freshly prepared resin at $-50^{\circ} \mathrm{C}$. UV-polymerization was started at $-50^{\circ} \mathrm{C}$ (overnight) and then continued for $4 \mathrm{~d}$ at temperatures gradually increasing from $-50^{\circ} \mathrm{C}$ to $-20^{\circ} \mathrm{C}(24 \mathrm{~h})$ and finally to $+20^{\circ} \mathrm{C}(24 \mathrm{~h})$. Thin sections $(70 \mathrm{~nm})$ were mounted on 200 -mesh formvar-coated nickel grids (Plano).

Post-embedding immunogold labeling (immunocytochemistry). For post-embedding immunogold labeling an earlier published protocol was modified (Pahner et al., 2003). Primary antibodies: VGLUT-1 guinea pig (1:200 dilution), VGAT guinea pig (1:50 dilution). All post-embedding steps except for the incubation with primary antibodies were performed at room temperature. For single and double immunolabeling sections (70 nm thick) were first incubated two times for $5 \mathrm{~min}$ in $0.1 \mathrm{M} \mathrm{PBT}$ (phosphate buffered saline, $0.001 \%$ Triton X-100, 0.001\% Tween 20, pH 7.4), then incubated for $90 \mathrm{~min}$ at room temperature in PBT supplemented with $2 \%$ BSA (bovine serum albumin, Sigma-Aldrich) and 5\% NGS (normal goat serum, PAN Biotech). The sections were then incubated with primary antibodies diluted in the same buffer overnight at $4^{\circ} \mathrm{C}$ in a humid chamber. After rinsing several times with PBT, the binding of primary antibodies was visualized by incubating with goat anti-rabbit or goat anti-guinea pig secondary antibodies either conjugated to 5 or 10 nm gold particles (British Biocell) in PBT supplemented with $0.5 \%$ acetylated BSA (Aurion), for $75 \mathrm{~min}$ in a humid chamber. Then grids were rinsed several times in PBT, PBS, and finally water. Thin sections were stained with $2 \%$ aqueous uranyl acetate (Merck) for $2 \mathrm{~min}$, and with lead citrate for $30 \mathrm{~s}$. Sections were examined using a Zeiss EM 900 equipped with a digital camera (Proscan $1 \mathrm{~K}$ Slow-Scan CCD-Camera). For negative controls primary antibodies were omitted.

\section{Results}

\section{Quantitative comparison of SVs enriched in either VGLUT-1} or VGAT by mass spectrometry

To selectively isolate SV subpopulations enriched with either VGLUT-1 or VGAT, we prepared an enriched SV fraction (LP2) as starting material to which Immunobeads containing either VGLUT-1 or VGAT antibodies were added (Takamori et al., 2000a,b). In agreement with our previous findings, EM-analysis of VGLUT-1/VGAT-coupled Immunobeads revealed specific binding of small homogenous SVs $(\sim 40 \mathrm{~nm})$ (supplemental Fig. 1 , available at www.jneurosci.org as supplemental material). Immunoblot analysis verified the specificity of the immunoisolated SV subpopulations with VGLUT-1 being largely absent from VGAT enriched immunoisolates and vice versa (Fig. 1).

Having confirmed the specificity of the SV immunoisolates, we next sought to quantitatively compare the proteomes of VGLUT-1- and VGAT-specific vesicles using isobaric tag for relative and absolute quantitation (iTRAQ) (Ross et al., 2004) together with tandem mass spectrometry (LC-MS/MS). To this end, VGLUT-1- and VGAT-immunoisolates were subjected to in-solution trypsin digestion and subsequently labeled with
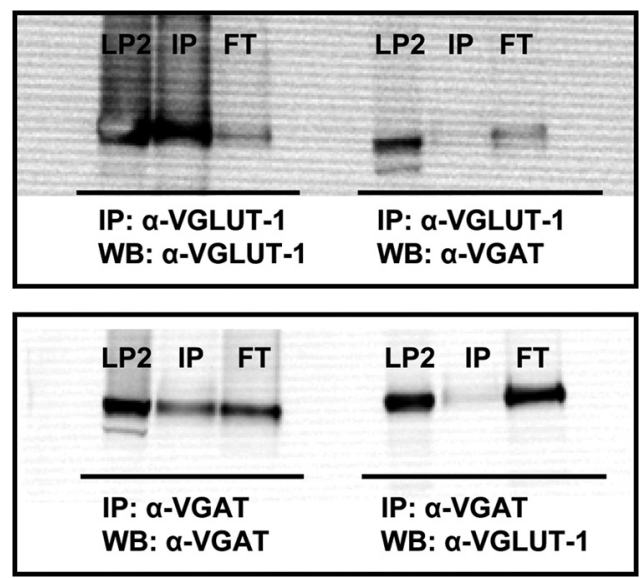

Figure 1. Immunoisolation of SVs using VGLUT-1- and VGAT-specific antibodies. Immunoblot analysis shows that VGLUT-1-isolated vesicles are largely depleted for VGAT vesicles (top panel) and VGAT-isolated vesicles are largely depleted of VGLUT-1 vesicles (bottom panel). LP2, Enriched synaptic vesicle fraction; IP, immunoprecipitated sample; FT, flow through (supernatant) after IP.

ITRAQ 114 or 115, respectively. The isobaric iTRAQ reagent forms covalent adducts to free $\mathrm{N}$ termini and lysine side chains and gives rise to differential reporter ions (i.e., $\mathrm{m} / \mathrm{z} 114$ and 115) upon peptide fragmentation during the MS/MS analysis. With this procedure, the relative abundance of each protein in VGLUT-1- and VGAT-isolated vesicles can be accurately quantified (supplemental Fig. 2, available at www.jneurosci.org as supplemental material).

To reduce the complexity of the sample before LC-MS/MS analysis, the digested sample was prefractionated off-line by SCX chromatography (supplemental Fig. 2, available at www. jneurosci.org as supplemental material). Ten SCX-fractions were collected that were then separately analyzed by reverse phase LC-MS/MS. Three independent biological replicates, with 2 technical replicates each, were conducted for the analysis. This procedure yielded close to 800 identified proteins (supplemental Table 1, available at www.jneurosci.org as supplemental material), almost twice as many as in our previous analysis (Takamori et al., 2006). In addition to previously characterized vesicle proteins which include proteins involved in trafficking (i.e., SNAREs), endocytosis, small GTPases, transporters and channels, we also identified several proteins postulated to be present on SVs that previously have been missed such as the chlorideproton exchangers $\mathrm{ClC} 3$ and $\mathrm{ClC}$. To ensure high quality of the quantitative comparison, we used conservative thresholds resulting in a refined pool of 460 quantified proteins (see Materials and Methods and supplemental Fig. 3, available at www.jneurosci.org as supplemental material, for details regarding protein quantitation, data normalization, and statistical analysis).

Comparison of the 460 proteins quantified by iTRAQ and LC-MS/MS revealed that VGLUT-1 was enriched approximately 5.5-fold in VGLUT-1 immunoisolates, whereas VGAT was enriched $>7.5$-fold in VGAT fractions (Fig. $2 A$ ), which provides a point of reference for all other proteins. Remarkably, the vast majority ( $\sim 90 \%$ ) of the proteins was found to be equally distributed between VGLUT-1 and VGAT vesicles, with a VGLUT-1/ VGAT ratio of close to 1 (Fig. 2; supplemental Table 1, available at www.jneurosci.org as supplemental material). These include most of the transport/channel proteins such as NTT4, the proline and aminophospholipid (APLT) transporters, the chloride proton exchanger $\mathrm{ClC} 3$, all subunits of the vacuolar proton ATPase (Fig. 2A), 


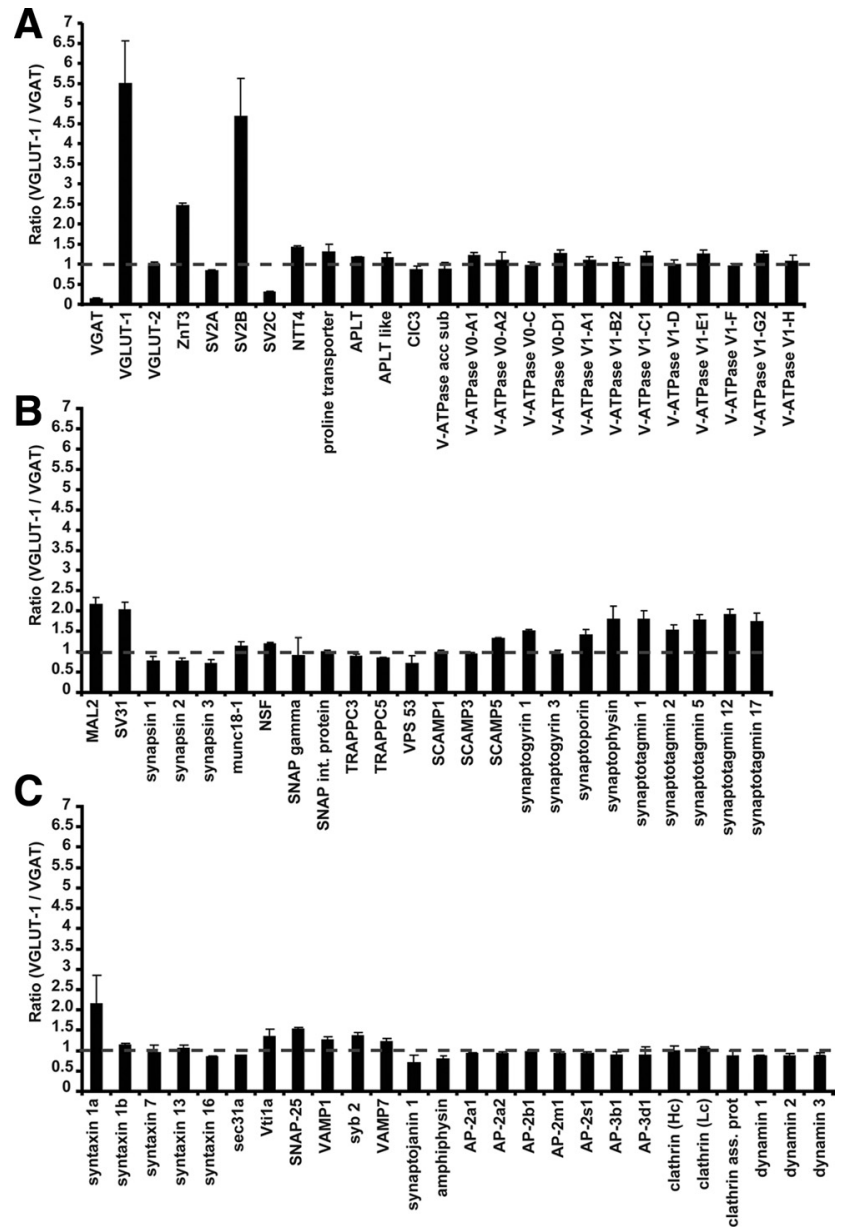

Figure 2. Quantitative proteomic comparison of immunoisolated VGLUT-1- and VGATspecific SVs reveals only few differences. Immunoisolated fractions were digested by trypsin and labeled with iTRAQ 114 or 115 , respectively. The labeled peptides were first fractionated by $S C X$ and subsequently analyzed by reverse phase liquid chromatography tandem mass spectrometry (LC-MS/MS). A-C, A total of 460 proteins were quantified in our study (supplemental Table 1, available at www.jneurosci.org as supplemental material), including vesicular transporters and ion channels $(\boldsymbol{A})$ and trafficking and SV membrane proteins $(\boldsymbol{B}, \boldsymbol{C})$. Dotted lines indicate a ratio of 1 , i.e., no difference between the two vesicle populations. Proteins identified to be significantly differentially expressed include in addition to the transporters VGLUT-1 and VGAT, the zinc transporter ZnT3, the vesicle membrane proteins SV2B, SV2C, SV31, synaptophysin, several synaptotagmin isoforms, the SNARE syntaxin 1a, and MAL2, a novel SV protein.

trafficking and SV membrane proteins (e.g., munc18-1, NSF, gamma SNAP, SNAP interacting protein (SNIP), SCAMPs, synaptogyrin and synaptoporin (Fig. 2 B), SNAREs (note that there is a difference between the syntaxin $1 \mathrm{a}$ and syntaxin $1 \mathrm{~b}$ ) and endocytosis-related proteins (e.g., AP-2/AP-3 complex, clathrin, synaptojanin 1, amphiphysin and dynamins) (Fig. 2C), small GTPases (Rabs), cytoskeletal proteins, cell surface, signaling proteins, and chaperones (supplemental Table 1, available at www.jneurosci.org as supplemental material). In some instances, subgroups of proteins like the synapsin phosphoproteins (I-III), involved in SV coupling to actin filaments (Bähler and Greengard, 1987; Greengard et al., 1993; Goold et al., 1995), showed mild preference toward VGAT containing vesicles; however, these differences did not reach statistical significance (Fig. $2 \mathrm{~B}$ ).

Only 5\% (25 proteins) and 6\% (27 proteins) of the quantified proteins were found to be significantly enriched in either VGLUT-1 or VGAT-specific vesicle subpopulations, respectively (supplemental Table 2, available at www.jneurosci.org as supple-
Table 1. SV proteins with significant differential expression

\begin{tabular}{llll}
\hline Protein name & $\begin{array}{l}\text { Ratio } \\
\text { (VGLUT-1/VGAT) }\end{array}$ & SD & Protein group \\
\hline VGLUT-1 & 5.50 & 1.06 & Transporter/Channel \\
SV2B & 4.68 & 0.94 & Transporter/Channel \\
ZnT3 & 2.46 & 0.06 & Transporter/Channel \\
MAL2 & 2.16 & 0.16 & Trafficking/SV membrane protein \\
SV31 & 2.02 & 0.19 & Trafficking/SV membrane protein \\
Synaptotagmin 1 & 1.80 & 0.20 & Trafficking/SV membrane protein \\
Synaptotagmin 12 & 1.92 & 0.12 & Trafficking/SV membrane protein \\
Synaptophysin & 1.80 & 0.33 & Trafficking/SV membrane protein \\
Syntaxin 1A & 2.16 & 0.68 & SNARE protein \\
VGAT & 0.13 & 0.03 & Transporter/Channel \\
SV2C & 0.29 & 0.03 & Transporter/Channel \\
\hline
\end{tabular}

mental material). Moreover, the majority of these proteins can be classified as loosely associated and/or contaminating proteins with a function unrelated to synaptic transmission. For the proteins known to be genuine SV proteins the majority belong to either transporter/channel proteins or trafficking/SV membrane proteins (Fig. 2; Table 1). Aside from VGLUT-1 and VGAT, differences in transporter/channel protein selectivity were found for the zinc transporter ( $\mathrm{ZnT} 3)$ that was largely associated with VGLUT-1 vesicles (2.5-fold enriched). This finding is in agreement with previous findings (Palmiter et al., 1996; Salazar et al., 2005). In addition, a specific association was detected for isoforms of SV2. SV2 represents a small family of SV proteins whose membrane topology (but not primary structure) is reminiscent of membrane transporters and that appear to function as modulators of $\mathrm{Ca}^{2+}$-dependent exocytosis (Chang and Südhof, 2009). Of the three known isoforms, SV2B and SV2C were selectively associated with VGLUT-1 and VGAT vesicles, respectively, whereas SV2A appears to be present in comparable amounts on both populations (Fig. $2 A$ ).

Trafficking and other SV membrane proteins with preferential enrichment in VGLUT-1 vesicles include SV31, synaptophysin, and several synaptotagmins (Fig. 2B). SV31, a recently identified SV membrane protein (Burré et al., 2007) with six predicted transmembrane helices and unknown function, has been previously reported to preferentially associate with VGLUT-1-positive nerve terminals in selected regions of the brain (e.g., plexiform layer of the olfactory bulb and piriform cortex) (Burré et al., 2007).

The enrichment of synaptophysin and the synaptotagmins (albeit moderate-twofold) in VGLUT-1 vesicles is surprising. Synaptophysin is widely used as general marker for all nerve terminals regardless of the neurotransmitter phenotype (Valtorta et al., 2004). However, recent immunofluorescence and electron microscopic data indeed suggest that synaptophysin is preferentially associated with VGLUT-1-positive terminals in the cerebral cortex (Bragina et al., 2007). Similarly, synaptotagmins 1,2 , and 12 are considered to represent the $\mathrm{Ca}^{2+}$-sensors for fast, synchronous neurotransmitter release in all neurons including GABAergic neurons (Maximov et al., 2007; Rizo and Rosenmund, 2008) (note that the differences for synaptotagmin 2 are not reaching significance levels). Our data now suggest that synaptotagmins may be less abundant on GABAergic vesicles, resulting in lower copy numbers that may have consequences for the kinetics of $\mathrm{Ca}^{2+}$-dependent release.

Among the spectrum of SNARE proteins identified, only syntaxin 1a showed preferential enrichment for VGLUT-1 immunoisolates $(\sim 2$-fold). By comparison, syntaxin $1 \mathrm{~b}$ was equally distributed on both vesicle subpopulations. Syntaxin $1 \mathrm{a}$ and $1 \mathrm{~b}$ 


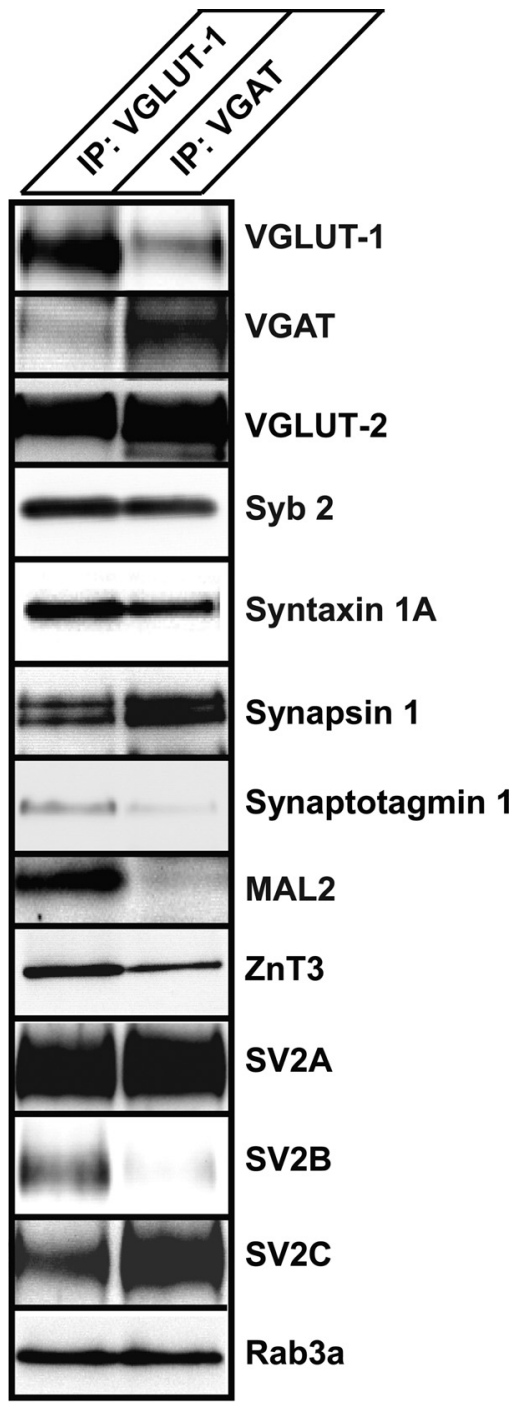

Figure 3. Differential enrichment of selected proteins on VGLUT-1- and VGAT-specific SVs, respectively, monitored by immunoblotting. Synaptotagmin 1, MAL2, and SV2B are enriched on VGLUT-1 vesicles, whereas synapsin 1 and SV2C are enriched in VGAT vesicles. VGLUT-2, syb 2 (VAMP2), SV2A, and Rab 3a all showed equal protein distribution in the two fractions. These data corroborate the findings obtained by quantitative MS (Fig. 2).

show differential expression patterns in all regions of the nervous system including the spinal cord, peripheral and CNS (RuizMontasell et al., 1996; Aguado et al., 1999), but it is, at least according to our knowledge, not known whether there is a correlation between the expression of syntaxin 1 isoforms and the vesicular transporters. Finally, we observed a VGLUT-1 preference for MAL2 that was previously identified in the SV-proteome (Takamori et al., 2006) but has hitherto not been found in neurons. MAL2 was consistently enriched 2.2-fold in VGLUT-1 vesicles suggesting that it may represent a novel and specific component of the glutamatergic SV proteome (see below).

To validate the findings obtained by quantitative MS, we analyzed the immunoisolated fractions by immunoblotting against a panel of selected SV proteins (Fig. 3). As expected, VGLUT-1 and VGAT transporter proteins were highly enriched in their respective immunoisolated vesicle fractions. By comparison, VGLUT-2, syb2 (VAMP2), and Rab 3a show equal distribution in both VGLUT-1- and VGAT-enriched SV fractions whereas syntaxin 1a, synaptotagmin 1, ZnT3, and MAL2 showed enrichment for VGLUT-1 vesicle fractions. On the other hand, synapsin 1 showed enrichment for VGAT vesicles. Moreover, SV2A showed equal distribution in VGLUT-1 and VGAT vesicle fractions, whereas SV2B and SV2C showed specificity for VGLUT-1 and VGAT vesicles, respectively. Together, these data are in excellent agreement with the iTRAQ MS-analysis (see Fig. 2).

To confirm that the differential distribution patterns are indeed indicative for a differential distribution between VGLUT-1positive glutamatergic and VGAT-positive GABAergic nerve terminals, we performed immunofluorescence microscopy using both primary cultured neurons and brain sections. First, we double labeled 12 days in vitro (DIV) rat hippocampal neurons using specific antibodies against VGLUT-1 or VGAT, either together, or in combination with selected SV proteins including synaptophysin, synapsin, and SV2A/2B/2C. As expected, VGLUT-1 and VGAT are present in distinct nerve terminals with no detectable overlap (Fig. 4, top panel), whereas both synaptophysin and synapsin I are expressed in all terminals (Fig. 4). Analysis of SV2 isoforms revealed that SV2A is present in both VGLUT-1- and VGAT-containing nerve terminals. In contrast, SV2B was not detectable in VGAT-positive terminals but colocalizes with VGLUT-1-positive terminals, whereas SV2C is colocalized with VGAT but also overlaps with VGLUT-1, thus resembling more the pattern obtained with SV2A.

Next, we compared the distributions of the SV2-isoforms with those of VGLUT-1 and VGAT in both hippocampal and cerebellar sections. In the hippocampus, SV2A immunoreactivity partially overlaps with both VGLUT-1 and VGAT staining in the $\mathrm{CA} 3$ area where the mossy fibers terminate (supplemental Fig. $4 A$, available at www.jneurosci.org as supplemental material), whereas SV2B yielded diffuse staining of the neuropil but was not detectable in the mossy fiber area (supplemental Fig. $4 B$, available at www.jneurosci.org as supplemental material). In the cerebellar cortex, SV2A colocalized with both VGLUT-1 and VGAT (Fig. $5 A, B$ ). In contrast, SV2B does not show significant overlap with VGAT but exhibits an almost complete overlap with the immunosignals of VGLUT-1 (Fig. 5C,D). Finally, SV2C colocalizes preferentially with VGAT especially in the Purkinje cell layer, but there was also some overlap with VGLUT-1 (Fig. 5 E, F), suggesting that this isoforms is also present in VGLUT-1-containing nerve terminals, albeit at a lower concentration. Together, these findings are largely in accordance with the differential distributions of the SV2 isoforms determined by MS-analysis of the VGLUT-1 and VGAT SV fractions (see Discussion).

\section{MAL2 is a novel integral membrane protein preferentially associated with VGLUT-1-containing SVs}

MAL2 (also named T-cell differentiation protein 2) is a member of the MAL family of presumably raft-associated membrane proteins that was originally identified as binding partner of TPD52, a cancer-associated protein of unknown function (Wilson et al., 2001). MAL2 is predicted to contain four transmembrane domains and thus exhibits a topology reminiscent of synaptophysins, synaptogyrins, and SCAMPs (Sánchez-Pulido et al., 2002). Its presence on VGLUT-1 SVs was unexpected, and since there are no reports describing the expression of MAL2 in neurons, we investigated whether MAL2 is a bona-fide membrane protein of SVs and if it is indeed selectively associated with presynaptic nerve terminals containing VGLUT-1. For characterization of MAL2, we generated a polyclonal rabbit antiserum using a previously described MAL2 peptide corresponding to the $\mathrm{N}$-terminal amino acids 13-28 as antigen (de Marco et al., 


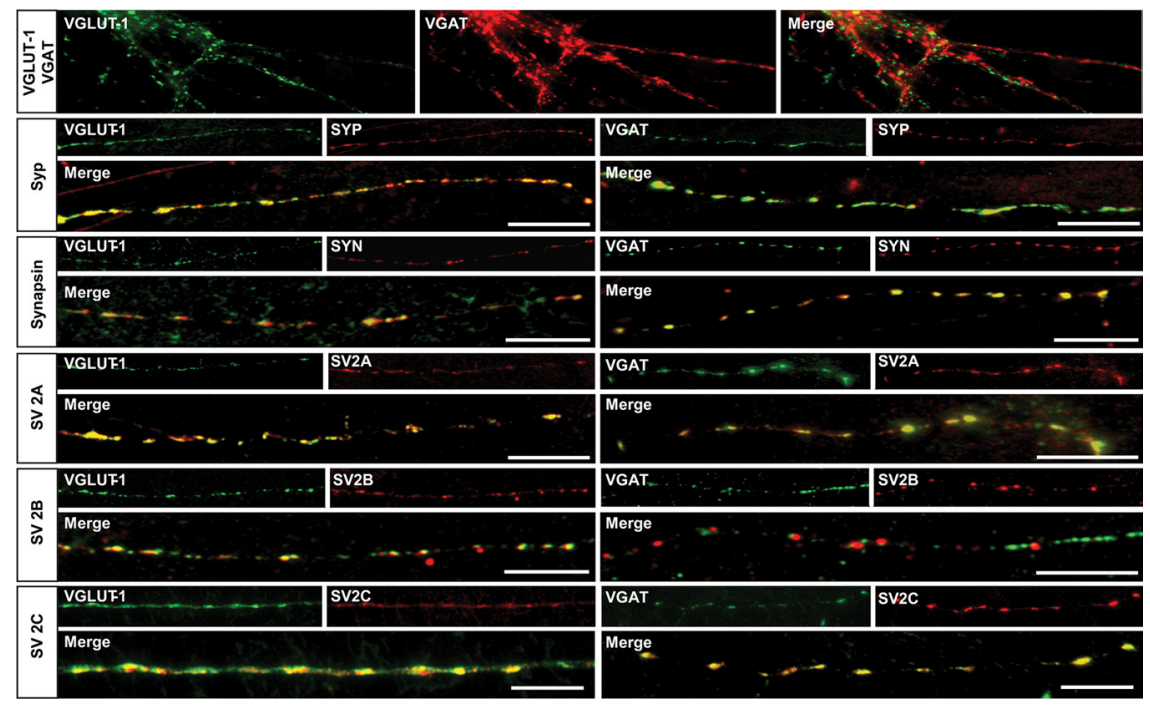

Figure 4. Association of differentially distributed SV proteins with glutamatergic and GABAergic nerve terminals in primary cultures of hippocampal neurons. Twelve DIV hippocampal neurons were double labeled with either VGLUT-1 or VGAT in combination with synaptophysin (syp), synapsin, SV2A, SV2B, and SV2C. Top panel, Double-labeling with VGLUT-1 and VGAT reveals non-overlapping punctuate staining showing that these transporters do not occur in the same nerve terminal. Synaptophysin (Syp) and Synapsin I, both ubiquitously expressed SV proteins, show a high degree of colocalization with both VGLUT-1 and VGAT. As expected, a similar result was obtained for SV2A. In contrast, SV2B colocalizes with VGLUT-1 but not with VGAT. SV2C, however, again colocalizes well with both VGLUT and VGAT.
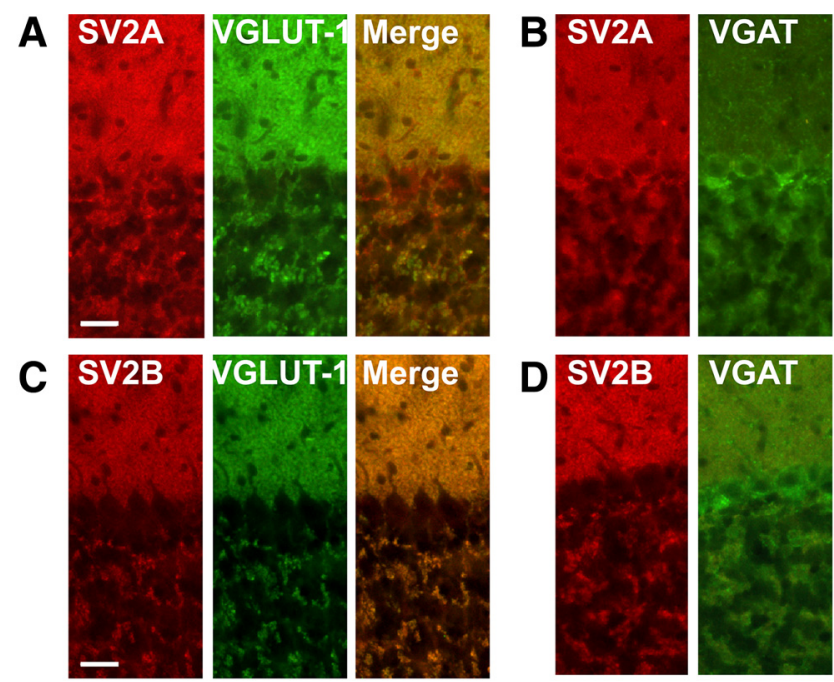

$\mathrm{E}$
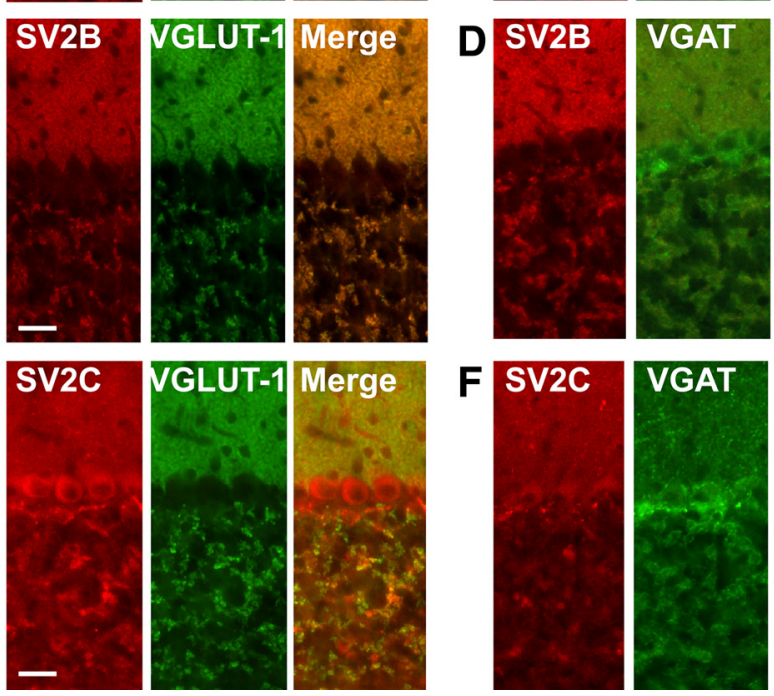

Figure 5. Colocalization of SV2 isoforms with VGLUT-1 and VGAT in sections of mouse cerebellum. $A-F$, Fluorescence microscopic analysis of SV2A $(\boldsymbol{A}, \boldsymbol{B}), \operatorname{SV2B}(\boldsymbol{C}, \boldsymbol{D})$, and $\operatorname{SV} 2 C(\boldsymbol{E}, \boldsymbol{F})$ all stained in red and either VGLUT-1 $(\boldsymbol{A}, \boldsymbol{C}, \boldsymbol{E})$ or VGAT $(\boldsymbol{B}, \boldsymbol{D}, \boldsymbol{F})$ stained in green. Scale bar, $100 \mu \mathrm{m}$.

2002). Following affinity-purification, the antibody recognized a single major band migrating at the expected size of 20 $\mathrm{kDa}$ (supplemental Fig. 5, available at www.jneurosci.org as supplemental material).
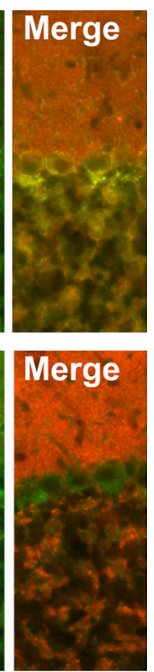

First, we performed TX-114 phase partitioning, which allows a separation of proteins carrying hydrophobic membrane anchor domains from all other proteins (Bordier, 1981). As expected for an integral membrane protein, MAL2 partitioned exclusively in the detergent phase (Fig. 6A). Next, we used limited proteolysis to test whether the $\mathrm{C}$ and $\mathrm{N}$ termini are exposed to the cytoplasm (as is the case for synaptophysins, synaptogyrins, and SCAMPs), or whether the protein has an inverse orientation. An enriched fraction of SVs was incubated with Pronase (Stenius et al., 1995), resulting in a loss of the MAL2 epitope as expected if the $\mathrm{N}$-terminal domain is cytoplasmic (Fig. 6B). The luminal epitope of synaptotagmin remained intact showing that intravesicular domains remained protected during proteolysis (Fig. $6 \mathrm{~B}$ ).

Next, we monitored the enrichment of MAL2 during the purification of SVs according to standard procedures (Huttner et al., 1983). As shown in Figure 6C, MAL2 cofractionates with bona-fide residents of SVs such as synaptophysin, Rab3a, VGLUT-2, and synaptotagmin, showing parallel enrichment particularly in the final purification steps. To confirm this specific association we performed immunogold electron microscopy on purified SVs. MAL2 labeling was selectively associated with vesicle profiles characteristic of SVs. Dual immunogold labeling with both VGLUT-1 and VGAT revealed subpopulations of SVs bearing both MAL2 and VGLUT-1 (Fig. 6D). However, occasional immunogold double labeling was also observed for VGAT and MAL2 (data not shown) suggesting that MAL2, while preferentially being associated with VGLUT-1 SVs, is not restricted to glutamatergic vesicles. We then surveyed different rat tissues to assess the expression levels of the MAL2 protein. MAL2 is expressed in all tissues examined, but at particularly high levels in both brain and liver (Fig. 6E).

The data described above show that MAL2 is an integral membrane protein with a predicted topology similar to the other vesicular tetraspan proteins that is highly expressed in brain and copurifies with SV markers. We therefore went on to further characterize MAL2 expression in neurons using immunocytochemistry of cultured rat hippocampal neurons (12 DIV) as well as of hippocampal and cerebellar sections. As shown in Figure 7, MAL2 antibodies labeled the soma, axons, and dendrites of both GABAergic and glutametergic neurons. In addition, examination of neurites revealed a punctate staining pattern characteristic for synaptic boutons. In 
agreement with the preferred association of MAL2 with VGLUT-1 SVs, these punctae showed strong colocalization with VGLUT-1, whereas little colocalization was observed with VGAT associated synaptic boutons (Fig. 7B). To obtain a more quantitative estimate of colocalization, we performed correlative line scan analyses of the stained synaptic boutons $(n=50)$. MAL2 showed strong correlation with VGLUT-1-containing presynaptic terminals $(\mathrm{Rr}=0.846)$ but weak association with VGAT $(\mathrm{Rr}=0.5381)$ (Fig. 7C).

Finally, we analyzed the distribution of MAL2 by immunocytochemistry on brain sections both at the light and electron microscopic level. Tissue and subcellular distribution analysis using immunofluorescence and post-embedding immunogold electron microscopy analyses were performed with mouse or rat cerebellar and hippocampal tissue. As seen in Figure $8 A$, MAL2 showed colocalization with VGLUT-1 in the mossy fiber tract of the CA3 area of hippocampus. Mossy fibers are contacted by a variety of interneurons and their terminals are clearly labeled by VGAT. However, there is almost no overlap with the MAL2 staining (Fig. $8 B$ ). In cerebellar sections, MAL2 staining is lower than in the hippocampus, suggesting lower expression levels. Despite this problem, a good colocalization between VGLUT-1 and MAL2 was seen in the molecular and (less clearly) in the granular layer (Fig. 8C) while no overlap with the VGAT immunoreactivity was observed (Fig. 8D).

The presence of MAL2 in VGLUT-1 terminals was confirmed by post-embedding immunogold labeling in hippocampal mossy fiber terminals where the coexistence of VGLUT-1 (5 nm gold particles) and MAL2 (10 nm gold particles) is clearly seen (Fig. $8 E$ ). Occasionally we observed MAL2- and VGLUT-1-specific immunogold particles on the same vesicle. However, considering the length of the antibody bridge between epitope and gold particle and the dense package of synaptic vesicles, a colocalization on the same vesicle is difficult to demonstrate free of doubt (detail in Fig. 8E). Similar results were obtained in the cerebellum. Here, labeling is seen in parallel fibers of the molecular layer and in mossy fiber terminals of the granular cell layer, with again occasionally double-labeled vesicles being observable (supplemental Fig. 4C,D, available at www.jneurosci.org as supplemental material). Interestingly, MAL2 immunogold reactivity was absent from VGLUT-2expressing climbing fiber terminals and the VGAT-expressing Basket cell terminals (data not shown, see also Fig. $8 E$ ).
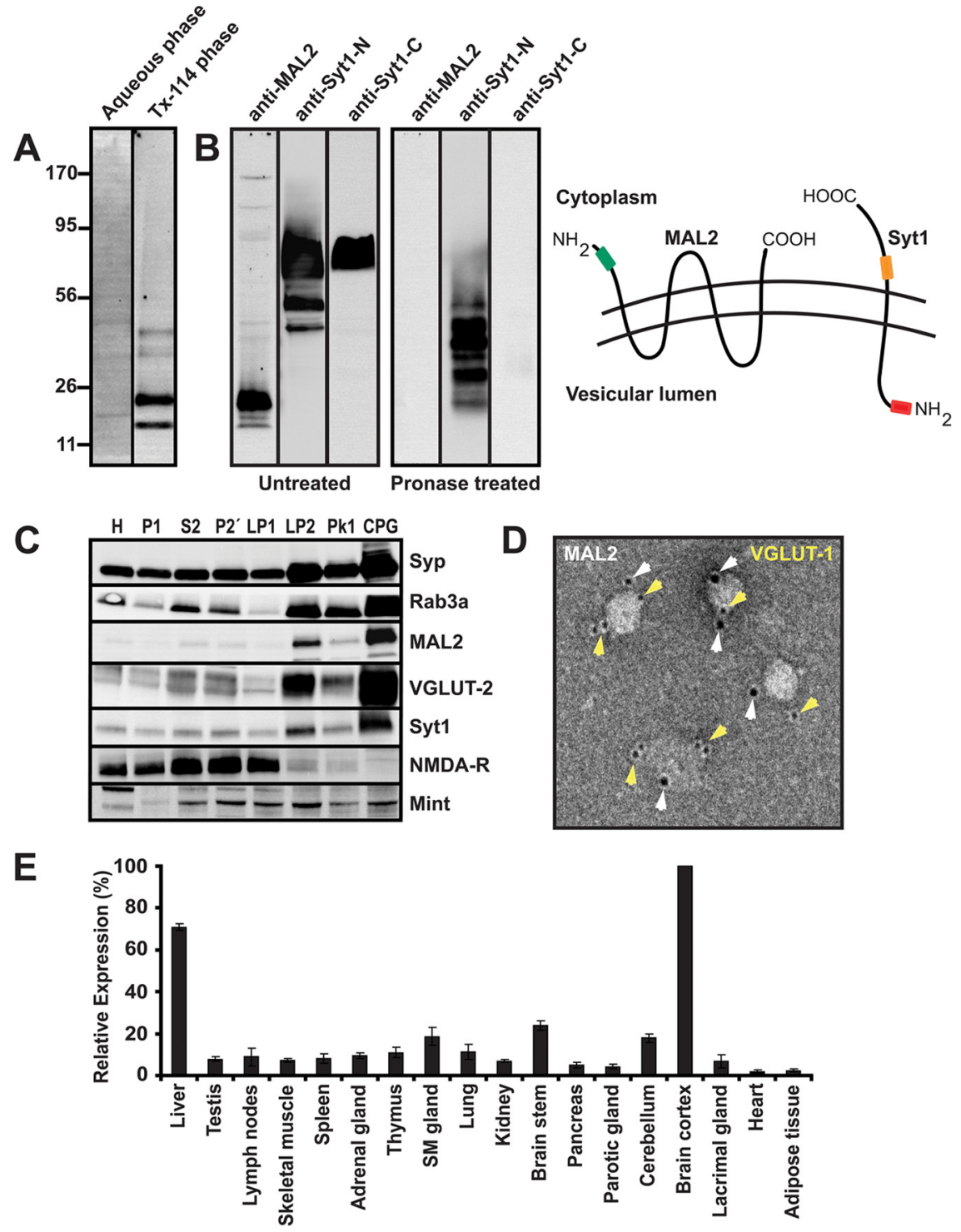

Figure 6. Biochemical characterization of MAL2. A, MAL2 enriches preferentially in the detergent phase during TX-114 phase separation indicating that it contains detergent-binding (transmembrane) domains. Rat brain homogenate (100 $\mu \mathrm{g})$ was dissolved in 10\% precondensated TX-114, and after phase separation the phases were analyzed by SDS-PAGE and immunoblotting using a MAL2-specific polyclonal antibody. $\boldsymbol{B}$, The N terminus of MAL2 is exposed on the vesicle surface. An enriched SV fraction (LP2) was either left untreated (left panel) or digested with Pronase (an unspecific protease) (right panel). Untreated MAL2 gives a distinct band $\sim 20 \mathrm{kDa}$ as expected, whereas the epitope (indicated by a green box in the right drawing) is not detectable after Pronase treatment. To ensure that luminal domains remained protected during protease treatment, we also probed for proteolysis of synaptotagmin I using monoclonal antibodies specific either for the cytoplasmic (orange) or luminal (red) regions. As expected, fragments carrying the $\mathrm{N}$-terminal epitope persisted whereas the C-terminal epitope was destroyed, confirming the selectivity of the proteolysis. C, MAL2 copurifies with SV proteins during subcellular fractionation. MAL2 cofractionates with bona-fide vesicle proteins such as synaptophysin, Rab3a, VGLUT-2, and Syt1. Note that the final fraction is devoid of contamination by postsynaptic membranes (NMDA-R1) whereas Mint, a soluble protein, is detectable but does not show enrichment. H, Homogenate; P1, crude nuclear pellet; S2, soluble fraction; P2' , crude synaptosomes; LP1, synaptosomal membrane fraction; LP2, crude SVs; PK1 (peak 1) and CPG, larger membranes and pure SVs, respectively, after separation by size exclusion chromatography on Controlled-Pore Glass beads (CPG). D, Immunogold electron microscopy analysis of SVs (negative staining) reveals colocalization of both MAL2 (10 nm gold) and VGLUT-1 ( $5 \mathrm{~nm}$ gold) on the same vesicles. $\boldsymbol{E}$, A survey of MAL2 expression by immunoblotting in different rat tissues reveals that MAL2 is highly expressed in the brain cortex and liver. Moderate to low expression is observed in brain stem and cerebellum and low expression is observed for the rest of the tested tissues. Membrane proteins in the homogenate samples (corresponding to $100 \mu \mathrm{g}$ of starting material) were extracted by TX-114 partitioning and analyzed by immunoblotting. The quantitative MAL2 immunoblot analysis was done in triplicates where the mean ( \pm SD) is presented in the histograms. The MAL2 signal (highest signal) in brain cortex was set to $100 \%$.

\section{Discussion}

In the present study, we have used a combination of high resolution mass spectrometry and chemical labeling (iTRAQ) to quantitatively compare the proteomes of immunoisolated glutamater- 

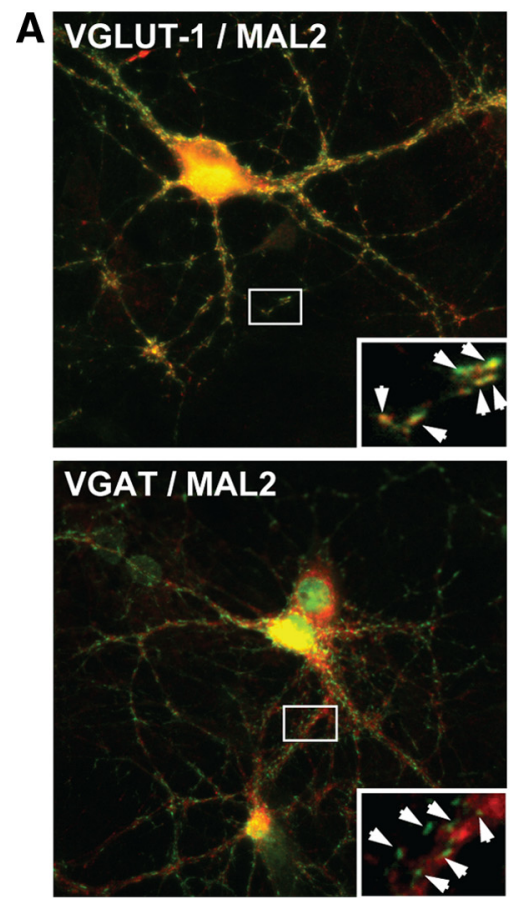
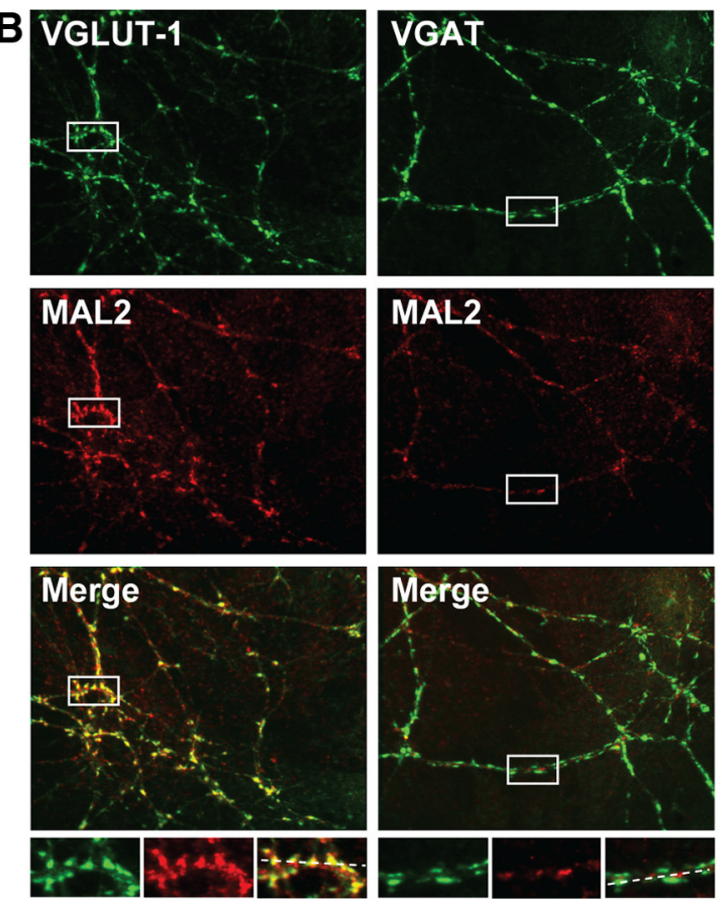
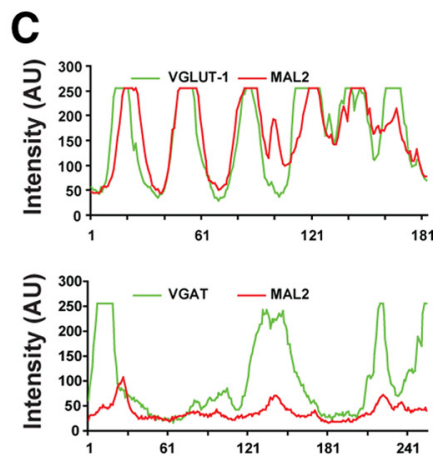

Figure 7. Association of MAL2 with glutamatergic nerve terminals in primary cultures of hippocampal neurons (see legend to Fig. 4 for details). $\boldsymbol{A}$, Immunostaining for MAL2 (red channel) is observed in the soma, axons and dendrites of both glutamatergic (VGLUT-1, green stain) and GABAergic (VGAT, green strain) neurons. Magnified views reveals punctuate staining for MAL2 as expected for a SV protein $(\boldsymbol{A}, \boldsymbol{B})$ with high degree of colocalization with VGLUT-1 in contrary to VGAT. $\boldsymbol{C}$, Correlative line-scans of synaptic boutons demonstrate selectivity of MAL2 for VGLUT-1positive nerve terminals.

gic (VGLUT-1) and GABAergic (VGAT) SVs. Surprisingly, only few vesicle membrane proteins showed significant enrichment in either VGLUT-1 or VGAT-containing vesicles, with the preferential association being confirmed by immunocytochemistry. In addition to previously characterized SV proteins these include MAL2, a protein with four transmembrane domains that we have identified as a novel membrane protein of SVs.

Several conclusions can be drawn from our findings. First, there does not appear to be any SV protein that perfectly matches the distribution of either VGLUT-1 or VGAT. This observation strongly supports the view that-at least for the major amino acid neurotransmitters in the CNS - the neurotransmitter phenotype of a given neuron is defined exclusively by the type of vesicular transporter-no other subunit or specific protein component appears to be required for filling the vesicle with the respective transmitter. This agrees with the fact that expression of VGLUT-1 in GABAergic neurons is sufficient to evoke exocytotic corelease of glutamate (Takamori et al., 2000a). It should be borne in mind that some of the vesicular carriers (VMATs and VGAT) transport several related transmitters, and in these instances it depends on the cytoplasmic concentration of the respective transmitter (determined by both biosynthetic enzymes and plasma membrane transporters) which transmitter will be loaded into the vesicles and released upon stimulation.

Second, our data suggest that the molecular architecture of SVs is largely conserved among neurons specific for different neurotransmitters. It is important to consider, however, that minor SV populations (such as cholinergic and aminergic/serotonergic vesicles) may harbor specialized proteins in addition to the transporters, which so far have escaped detection. Furthermore, we cannot exclude that low-abundance membrane proteins, associated either with VGLUT-1 or VGAT SVs, might have escaped detection, despite the high sensitivity of our MS-analysis. Intriguingly, most of the few differentially expressed proteins include isoforms of ubiquitously distributed protein families such as the SV2s, synaptotagmins syntaxins, and synaptophysins. While it is largely unknown whether these isoforms are fully redundant or represent (at least partial) functional differentiation, it strengthens the view that each neuron expresses at least one member of all of the major SV proteins.

Third, as above mentioned, none of the proteins preferentially associated with either VGLUT-1 or VGAT reached the enrichment levels of the transporters themselves (with SV2B being a possible exception), suggesting that the expression pattern of these proteins is not exclusively linked to anyone of the transporters. For glutamatergic vesicles it is noteworthy that we have only analyzed SVs carrying one of the glutamate transporters, and a protein associated with both VGLUT-1 and VGLUT-2 is thus expected to show a lower enrichment than VGLUT-1. However, in general, our immunocytochemical data confirm that there is no complete match: For instance, SV2B is perfectly colocalized with VGLUT-1 in the cerebellum but not in the hippocampus where expression in VGLUT-1-positive mossy fiber terminals is barely detectable. On the other side, a perfect colocalization is obtained in mossy fiber terminals between VGLUT-1 and MAL2, which is less obvious in the cerebellar granular layer. Several of the proteins identified here to be enriched preferentially on VGLUT-1 vesicles were previously shown to associate preferentially with glutamatergic synapses. These include the zinc transporter ZnT3 (Palmiter et al., 1996; Salazar et al., 2005), SV31, a multispan membrane proteins of SV that shows region-specific expression pattern and was found to be associated preferentially, but not exclusively, with VGLUT-1-positive nerve terminals (Burré et al., 2007) and, surprisingly, synaptophysin (Bragina et al., 2007), that is widely used as general marker for all nerve terminals regardless of the transmitter phenotype. Furthermore, it has been shown previously that SV2A is expressed ubiquitously 
throughout all brain regions while the expression patterns of SV2B and SV2C are more restricted (Bajjalieh et al., 1994; Janz and Südhof, 1999), with SV2B expression observed by in situ hybridization both in glutamatergic and GABAergic neurons (Bajjalieh et al., 1994).

Fourth, a word of caution is indicated with respect to the compositional homogeneity suggested by our quantitative comparison of VGLUT-1- and VGATcontaining SV populations. The fact that differentially expressed proteins or protein isoforms do not form perfectly overlapping groups suggests the presence of "molecular maps" in the brain that are anatomically more complex. Apparently, these maps do not follow transmitter phenotypes, and it remains to be established to which extent they define functional heterogeneities between the corresponding synapses. Such heterogeneous distribution patterns of individual SV proteins may result in a higher diversity in the molecular composition of SVs than suggested by the bulk biochemical analysis of immunoisolated fractions. Furthermore, distinctions in posttranslational processing might also exist between VGLUT-1 and VGAT SVs that were not detected in our study.

The group of proteins enriched on VGLUT-1 vesicles includes MAL2, a novel SV protein. MAL2 belongs to a small family of transmembrane proteins with three members including (besides MAL2) the proteins MAL (also referred to as VIP17) and BENE (Alonso and Weissman, 1987; Zacchetti et al., 1995; de Marco et al., 2001). Like some other SV proteins, MAL proteins are not specific for neurons but rather expressed in a wide range of tissues (Marazuela et al., 2004). Both MAL and MAL2 have been studied in polar differentiated cells where they were found to be specifically associated with organelles involved in apical trafficking. In these cells, both proteins are enriched in detergentresistant membranes (rafts) (Pérez et al., 1997; Cheong et al., 1999; de Marco et al., 2002). Indeed, changes of the protein expression levels using either overexpression or downregulation strongly perturbed apical trafficking, including both vesicle formation and endocytosis (Puertollano et al., 1997; Cheong et al., 1999; de Marco et al., 2002; Martín-Belmonte et al., 2003), with the functions of MAL and MAL2 being suggested to be different (de Marco et al., 2002; Maximov et al., 2007). These observations functionally implicate MAL proteins in vesicular trafficking. However, similar to the other vesicular "tetraspanins" including the synaptophysins, synaptogyrins, and SCAMPs, there are presently no ideas how they may function at the molecular level.

So far, we can only speculate to which extent the differential protein distributions observed here are functionally significant. With exception of ZnT3 that is known to accumulate $\mathrm{Zn}^{2+}$ in a subset of glutamatergic SVs (for review, see Paoletti et al., 2009), all
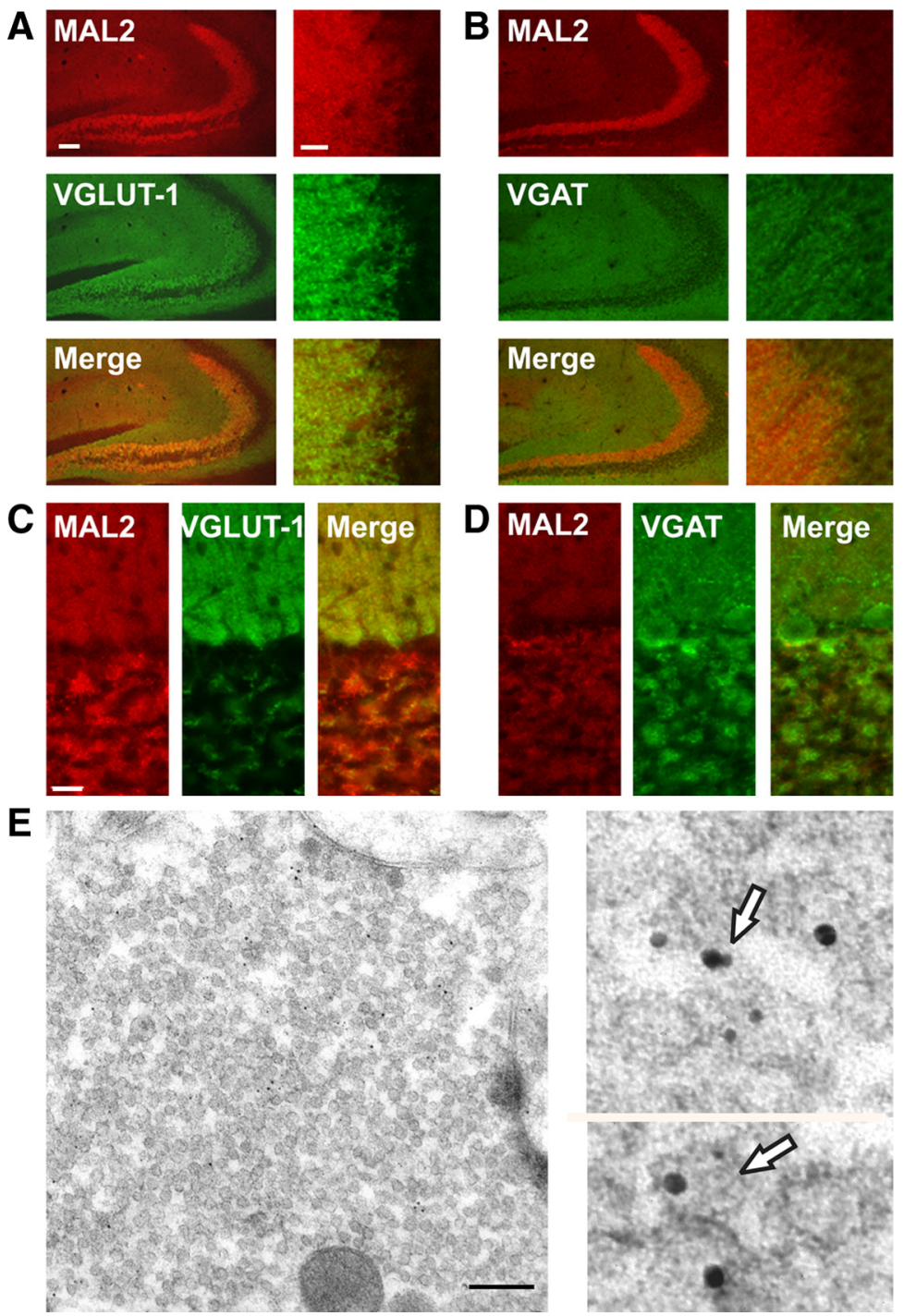

Figure 8. Immunofluorescence and EM analysis of MAL2 in rat and mouse hippocampal and cerebellar sections. $\boldsymbol{A}, \boldsymbol{B}$, Fluores(he overview reveals the colocalization between VGLUT- 1 and MAL2 but not between

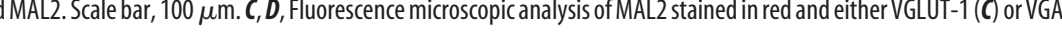
between MAL2 and VGAT. $E$, Double immunogold labeling of a mossy fiber terminal from the rat hippocampal CA3 area indicates the synaptic and vesicular coexistence of MAL2 (10 nm gold) and VGLUT-1 ( $5 \mathrm{~nm}$ gold). The magnified images (two right panels) represents areas from independent samples are therefore not marked in the overview (left panel). Scale bar, $200 \mathrm{~nm}$.

other proteins (at least as far known) play a role in SV trafficking. For instance, our data suggest that (perhaps only a subset of) GABAergic vesicles may have a lower concentration of synaptotagmins and synaptophysins than glutamatergic vesicles, which may contribute to the fine-tuning of the release characteristics of the respective nerve terminals. In this respect a putative coexistence of VGLUT-2 or 3 on GABAergic or aminergic vesicles may modulate vesicular filling. However, the fact that the similarities are far more dominating than the differences establishes that glutamatergic and GABAergic vesicles comprise only minor variations of a molecular architecture that is largely common to both excitatory and inhibitory SVs.

\section{References}

Aguado F, Majó G, Ruiz-Montasell B, Llorens J, Marsal J, Blasi J (1999) Syntaxin $1 \mathrm{~A}$ and $1 \mathrm{~B}$ display distinct distribution patterns in the rat peripheral nervous system. Neuroscience 88:437-446.

Ahnert-Hilger G, Höltje M, Pahner I, Winter S, Brunk I (2003) Regulation 
of vesicular neurotransmitter transporters. Rev Physiol Biochem Pharmacol 150:140-160.

Alonso MA, Weissman SM (1987) cDNA cloning and sequence of MAL, a hydrophobic protein associated with human T-cell differentiation. Proc Natl Acad Sci U S A 84:1997-2001.

Bähler M, Greengard P (1987) Synapsin Ibundles F-actin in a phosphorylationdependent manner. Nature 326:704-707.

Bajjalieh SM, Frantz GD, Weimann JM, McConnell SK, Scheller RH (1994) Differential expression of synaptic vesicle protein 2 (SV2) isoforms. J Neurosci 14:5223-5235.

Becher A, Drenckhahn A, Pahner I, Margittai M, Jahn R, Ahnert-Hilger G (1999) The synaptophysin-synaptobrevin complex: a hallmark of synaptic vesicle maturation. J Neurosci 19:1922-1931.

Bethani I, Lang T, Geumann U, Sieber JJ, Jahn R, Rizzoli SO (2007) The specificity of SNARE pairing in biological membranes is mediated by both proof-reading and spatial segregation. EMBO J 26:3981-3992.

Blondeau F, Ritter B, Allaire PD, Wasiak S, Girard M, Hussain NK, Angers A, Legendre-Guillemin V, Roy L, Boismenu D, Kearney RE, Bell AW, Bergeron JJ, McPherson PS (2004) Tandem MS analysis of brain clathrin-coated vesicles reveals their critical involvement in synaptic vesicle recycling. Proc Natl Acad Sci U S A 101:3833-3838.

Bordier C (1981) Phase separation of integral membrane proteins in Triton X-114 solution. J Biol Chem 256:1604-1607.

Bragina L, Candiracci C, Barbaresi P, Giovedì S, Benfenati F, Conti F (2007) Heterogeneity of glutamatergic and GABAergic release machinery in cerebral cortex. Neuroscience 146:1829-1840.

Brose N, Petrenko AG, Südhof TC, Jahn R (1992) Synaptotagmin: a calcium sensor on the synaptic vesicle surface. Science 256:1021-1025.

Burger PM, Mehl E, Cameron PL, Maycox PR, Baumert M, Lottspeich F, De Camilli P, Jahn R (1989) Synaptic vesicles immunoisolated from rat cerebral cortex contain high levels of glutamate. Neuron 3:715-720.

Burré J, Volknandt W (2007) The synaptic vesicle proteome. J Neurochem 101:1448-1462.

Burré J, Beckhaus T, Schägger H, Corvey C, Hofmann S, Karas M, Zimmermann H, Volknandt W (2006) Analysis of the synaptic vesicle proteome using three gel-based protein separation techniques. Proteomics 6:6250-6262.

Burré J, Zimmermann H, Volknandt W (2007) Identification and characterization of SV31, a novel synaptic vesicle membrane protein and potential transporter. J Neurochem 103:276-287.

Chang WP, Südhof TC (2009) SV2 renders primed synaptic vesicles competent for $\mathrm{Ca}^{2+}$-induced exocytosis. J Neurosci 29:883-897.

Chapman ER, Hanson PI, An S, Jahn R (1995) Ca2 + regulates the interaction between synaptotagmin and syntaxin 1. J Biol Chem 270:23667-23671.

Cheong KH, Zacchetti D, Schneeberger EE, Simons K (1999) VIP17/MAL, a lipid raft-associated protein, is involved in apical transport in MDCK cells. Proc Natl Acad Sci U S A 96:6241-6248.

Coughenour HD, Spaulding RS, Thompson CM (2004) The synaptic vesicle proteome: a comparative study in membrane protein identification. Proteomics 4:3141-3155.

de Marco MC, Kremer L, Albar JP, Martinez-Menarguez JA, Ballesta J, Garcia-Lopez MA, Marazuela M, Puertollano R, Alonso MA (2001) BENE, a novel raft-associated protein of the MAL proteolipid family, interacts with caveolin-1 in human endothelial-like ECV304 cells. J Biol Chem 276:23009-23017.

de Marco MC, Martín-Belmonte F, Kremer L, Albar JP, Correas I, Vaerman JP, Marazuela M, Byrne JA, Alonso MA (2002) MAL2, a novel raft protein of the MAL family, is an essential component of the machinery for transcytosis in hepatoma HepG2 cells. J Cell Biol 159:37-44.

Edelmann L, Hanson PI, Chapman ER, Jahn R (1995) Synaptobrevin binding to synaptophysin: a potential mechanism for controlling the exocytotic fusion machine. EMBO J 14:224-231.

Edwards RH (2007) The neurotransmitter cycle and quantal size. Neuron 55:835-858.

Fremeau RT Jr, Burman J, Qureshi T, Tran CH, Proctor J, Johnson J, Zhang H, Sulzer D, Copenhagen DR, Storm-Mathisen J, Reimer RJ, Chaudhry FA, Edwards RH (2002) The identification of vesicular glutamate transporter 3 suggests novel modes of signaling by glutamate. Proc Natl Acad Sci U S A 99:14488-14493.

Goold R, Chan KM, Baines AJ (1995) Coordinated regulation of synapsin I interaction with F-actin by $\mathrm{Ca} 2+/$ calmodulin and phosphorylation: inhibition of actin binding and bundling. Biochemistry 34:1912-1920.

Greengard P, Valtorta F, Czernik AJ, Benfenati F (1993) Synaptic vesicle phosphoproteins and regulation of synaptic function. Science 259:780785.

Hell JW, Jahn R (1994) Preparation of synaptic vesicles from mammalian brain, Ed 1. New York: Academic.

Huttner WB, Schiebler W, Greengard P, De Camilli P (1983) Synapsin I (protein I), a nerve terminal-specific phosphoprotein. III. Its association with synaptic vesicles studied in a highly purified synaptic vesicle preparation. J Cell Biol 96:1374-1388.

Jahn R, Schiebler W, Ouimet C, Greengard P (1985) A 38,000-dalton membrane protein (p38) present in synaptic vesicles. Proc Natl Acad Sci U S A 82:4137-4141.

Jahn R, Südhof TC (1994) Synaptic vesicles and exocytosis. Annu Rev Neurosci 17:219-246.

Janz R, Südhof TC (1999) SV2C is a synaptic vesicle protein with an unusually restricted localization: anatomy of a synaptic vesicle protein family. Neuroscience 94:1279-1290.

Laemmli UK (1970) Cleavage of structural proteins during the assembly of the head of bacteriophage T4. Nature 227:680-685.

Li KW, Miller S, Klychnikov O, Loos M, Stahl-Zeng J, Spijker S, Mayford M, Smit AB (2007) Quantitative proteomics and protein network analysis of hippocampal synapses of CaMKIIalpha mutant mice. J Proteome Res 6:3127-3133.

Marazuela M, Acevedo A, García-López MA, Adrados M, de Marco MC, Alonso MA (2004) Expression of MAL2, an integral protein component of the machinery for basolateral-to-apical transcytosis, in human epithelia. J Histochem Cytochem 52:243-252.

Martín-Belmonte F, Martínez-Menárguez JA, Aranda JF, Ballesta J, de Marco MC, Alonso MA (2003) MAL regulates clathrin-mediated endocytosis at the apical surface of Madin-Darby canine kidney cells. J Cell Biol 163:155-164.

Maximov A, Shin OH, Liu X, Südhof TC (2007) Synaptotagmin-12, a synaptic vesicle phosphoprotein that modulates spontaneous neurotransmitter release. J Cell Biol 176:113-124.

Morciano M, Burré J, Corvey C, Karas M, Zimmermann H, Volknandt W (2005) Immunoisolation of two synaptic vesicle pools from synaptosomes: a proteomics analysis. J Neurochem 95:1732-1745.

Pahner I, Höltje M, Winter S, Takamori S, Bellocchio EE, Spicher K, Laake P, Nürnberg B, Ottersen OP, Ahnert-Hilger G, Nümberg B (2003) Functional G-protein heterotrimers are associated with vesicles of putative glutamatergic terminals: implications for regulation of transmitter uptake. Mol Cell Neurosci 23:398-413.

Palmiter RD, Cole TB, Quaife CJ, Findley SD (1996) ZnT-3, a putative transporter of zinc into synaptic vesicles. Proc Natl Acad Sci U S A 93:14934-14939.

Paoletti P, Vergnano AM, Barbour B, Casado M (2009) Zinc at glutamatergic synapses. Neuroscience 158:126-136.

Pérez P, Puertollano R, Alonso MA (1997) Structural and biochemical similarities reveal a family of proteins related to the MAL proteolipid, a component of detergent-insoluble membrane microdomains. Biochem Biophys Res Commun 232:618-621.

Puertollano R, Li S, Lisanti MP, Alonso MA (1997) Recombinant expression of the MAL proteolipid, a component of glycolipid-enriched membrane microdomains, induces the formation of vesicular structures in insect cells. J Biol Chem 272:18311-18315.

Rizo J, Rosenmund C (2008) Synaptic vesicle fusion. Nat Struct Mol Biol 15:665-674.

Ross PL, Huang YN, Marchese JN, Williamson B, Parker K, Hattan S, Khainovski N, Pillai S, Dey S, Daniels S, Purkayastha S, Juhasz P, Martin S, Bartlet-Jones M, He F, Jacobson A, Pappin DJ (2004) Multiplexed protein quantitation in Saccharomyces cerevisiae using amine-reactive isobaric tagging reagents. Mol Cell Proteomics 3:1154-1169.

Ruiz-Montasell B, Aguado F, Majó G, Chapman ER, Canals JM, Marsal J, Blasi J (1996) Differential distribution of syntaxin isoforms $1 \mathrm{~A}$ and $1 \mathrm{~B}$ in the rat central nervous system. Eur J Neurosci 8:2544-2552.

Salazar G, Craige B, Love R, Kalman D, Faundez V (2005) Vglutl and ZnT3 co-targeting mechanisms regulate vesicular zinc stores in PC12 cells. J Cell Sci 118:1911-1921.

Sánchez-Pulido L, Martín-Belmonte F, Valencia A, Alonso MA (2002) 
MARVEL: a conserved domain involved in membrane apposition events. Trends Biochem Sci 27:599-601.

Schlüter OM, Khvotchev M, Jahn R, Südhof TC (2002) Localization versus function of Rab3 proteins. Evidence for a common regulatory role in controlling fusion. J Biol Chem 277:40919-40929.

Stenius K, Janz R, Südhof TC, Jahn R (1995) Structure of synaptogyrin (p29) defines novel synaptic vesicle protein. J Cell Biol 131:1801-1809.

Sudhof TC (2004) The synaptic vesicle cycle. Annu Rev Neurosci 27:509-547.

Takamori S, Rhee JS, Rosenmund C, Jahn R (2000a) Identification of a vesicular glutamate transporter that defines a glutamatergic phenotype in neurons. Nature 407:189-194.

Takamori S, Riedel D, Jahn R (2000b) Immunoisolation of GABA-specific synaptic vesicles defines a functionally distinct subset of synaptic vesicles. J Neurosci 20:4904-4911.

Takamori S, Rhee JS, Rosenmund C, Jahn R (2001) Identification of differentiation-associated brain-specific phosphate transporter as a second vesicular glutamate transporter (VGLUT2). J Neurosci 21:RC182.

Takamori S, Holt M, Stenius K, Lemke EA, Grønborg M, Riedel D, Urlaub H, Schenck S, Brügger B, Ringler P, Müller SA, Rammner B, Gräter F, Hub JS, De Groot BL, Mieskes G, Moriyama Y, Klingauf J, Grubmüller H,
Heuser J, Wieland F, Jahn R (2006) Molecular anatomy of a trafficking organelle. Cell 127:831-846.

Takumi Y, Ramírez-León V, Laake P, Rinvik E, Ottersen OP (1999) Different modes of expression of AMPA and NMDA receptors in hippocampal synapses. Nat Neurosci 2:618-624.

Thingholm TE, Larsen MR (2009) The use of titanium dioxide microcolumns to selectively isolate phosphopeptides from proteolytic digests. Methods Mol Biol 527:57-66, xi.

Towbin H, Staehelin T, Gordon J (1979) Electrophoretic transfer of proteins from polyacrylamide gels to nitrocellulose sheets: procedure and some applications. Proc Natl Acad Sci U S A 76:4350-4354.

Valtorta F, Pennuto M, Bonanomi D, Benfenati F (2004) Synaptophysin: leading actor or walk-on role in synaptic vesicle exocytosis? Bioessays 26:445-453.

Wilson SH, Bailey AM, Nourse CR, Mattei MG, Byrne JA (2001) Identification of MAL2, a novel member of the mal proteolipid family, though interactions with TPD52-like proteins in the yeast two-hybrid system. Genomics 76:81-88.

Zacchetti D, Peränen J, Murata M, Fiedler K, Simons K (1995) VIP17/MAL, a proteolipid in apical transport vesicles. FEBS Lett 377:465-469. 